\title{
XXI. Relations of surface-resistance at electrodes to various electrical phenomena
}

\section{G. Gore LL.D F.R.S.}

To cite this article: G. Gore LL.D F.R.S. (1886) XXI. Relations of surface-resistance at electrodes to various electrical phenomena, Philosophical Magazine Series 5, 21:129, 145-151, DOI: $10.1080 / 14786448608627824$

To link to this article: http://dx.doi.org/10.1080/14786448608627824

册 Published online: 29 Apr 2009.

Submit your article to this journal $[\pi$

Џ Article views: 2

Q View related articles $₫$ 
heen obtained, the next is got from it by the usual "rules of derivation " modified from those of Arbogast to suit the case where, as here, each differential coefficient is replaced by its appropriate submultiple. (Vid. Do Morgan's 'Calculus,' p. 330.)

5. In the 'Proceedings of the Edinb. Math. Soc.' 1884-85, pp. 95-100, Professor Chrystal has a note on "A Method for obtaining the Differential Equation of an Algebraical Curve." In the case of the cubic he gets for the non-zero side of the equation a determinant of the 6 th order which he says can be simplified further. I find that when this simplification is made, and $y_{2}, y_{3}, \ldots$ are expressed in terms of $\alpha, \beta, \ldots$, the result agrees perfectly with the above**

Bishopton, Glasgow, January 9, 1886.

XXI. Relations of Surface-resistance at Electrodes to various Electrical Phenomena. By G. Gore, LL.D., F.R.S.†

T $N$ some experiments described in a paper on "Evidence 1 respecting the Reality of 'Transfer-resistance' in Electrolytic Cells," read before the Birmingham Philosophical Society, January $21,1886 \ddagger$, I found that when a current of voltaic electricity was passed from dilute nitric or sulphuric acid, or strong nitric acid, into the surface of a thin platinum bottle used as a cathode, the temperature of the bottle snddenly rose, notwithstanding that certain amounts of heat must have been absorbed by the copious liberation of hydrogen which occurred, and by that substance assuming the gaseous state, each at the surface of the bottle; and I further found that this rise of temperature was not due to heat produced by ordinary conduction-resistance of the bottle or of the liquid, nor to resistance of any kind at the anode, and that it was due to some influence other than that of chemical change, at the surfaces of mutual contact of the liquid and bottle ; and further, that it varied in quantity directly as the amount of "resistance" to the passage of the current into the surface of the bottle. I also found similar thermal effects of "resistance" at the surface of the bottle, when the latter was used as an anode.

* The differential equation of the cubic appears to have been first given by Mr. Samuel Roberts in the 'Educational Times.' The question and solution are reprinted in 'Math. from Educ. Times,' x. pp. 47, 48. The date of the first publication of the question, which unfortunately can in no case be got with certainty from the Reprint, should probably be 1868.T. M. (January 18).

+ Communicated by the Author: read before the Birmingham Philosophical Society, January 21st, 1886.

$\mp$ See p. 130 of the present Number.

Phil. Mag. S. 5. Vol. 21. No. 129. Feb. 1886. 
In a previous investigation on "transfer-resistance" (Proc. Royal Soc. vol. xxxviii. p. 209) I also found "that a species of electric resistance distinct from that of polarization and of ordinary couduction-resistance, varying greatly in amount in different cases, exists at the surfaces of mutual contact of metals and liquids in electrolytic and voltaic cells. That this resistance varies largely in amount with different metals in the same solution, and with the same metal in different solutions," "and is usually small with easily corrodible metals which form readily soluble salts, and large with those which are not corroded ;" and "that the same voltaic current was resisted in different degrees by every different metal when employed as an anode, and when used as a cathode;" "and that the resistance at the anode was usually smaller than that at the cathode ;" and "that by rise of temperature 'transfer-resistance' was usually and considerably reduced." This "transfer-resistance" differs essentially from electric potential, because it is incapable of producing a current.

The present experiments were made for the purpose of examining some relations of this "surface-resistance" to various electrical phenomena. I call it "surface-resistance" in the present case, because, in consequence of omission of stirring, it includes other forms of resistance besides that of "transfer" at the surfaces of mutual contact of the metals and liquids employed.

First.-In cases of thermoelectric currents produced by heating the junction of a metal and electrolyte. We know that when heat is applied to one of the two ends of a piece of non-corrodible metal in contact with opposite parts of an electrolyte, an electric current is usually produced, and we infer from the principle of conservation of energy that when such a current occurs heat is absorbed and disappears at or near the heated junction, and is converted into and produces the current.

In order to determine whether the relative amounts of "surface-resistance" at the junctions of such a thermo-couple vary with temperature, and also whether the direction of current produced by such a couple is influenced by the relative total amounts of such "resistance" in the two directions in the circuit, I made the following experiments :-

The liquids employed were dilute sulphuric and nitric acids, each being composed of one volume of strong acid and ten volumes of water; and the electrodes were two perfectly similar sheets of platinum, each having a total immersed area of surface of about $24 \cdot 0 \mathrm{sq}$. $\mathrm{cm}$.

The thermoelectric apparatus consisted of a vertical glass 
tube, open at its upper end, $19.0 \mathrm{~cm}$. high, and $3.0 \mathrm{~cm}$. internal diameter (see sketch). One of the platinum plates was suspended vertically in the upper end of the tube by means of a platinum wire; and the other, welded to a stout platinum wire, was supported vertically in the lower end by passing the wire through a cork fixed in a hole in a vulcanized indiarubber bung which closed the end of the tube. The two plates were $9 \cdot 0 \mathrm{~cm}$. apart. The glass tube was nearly filled with the acid liquid ; its upper end was surrounded by a water-bath, the water in which was heated by

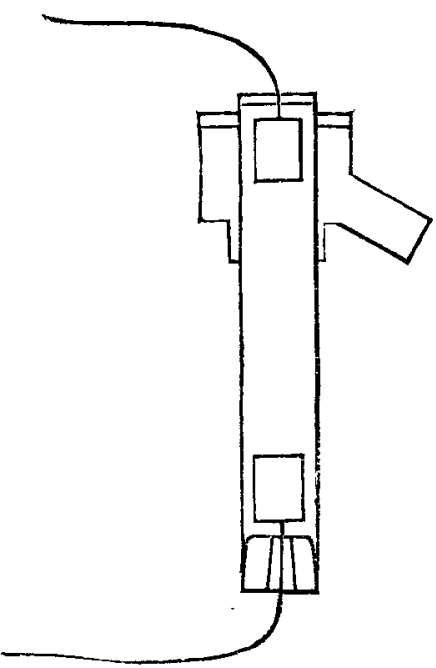
applying a flame to a projecting arm of the bath. The bulb of a thermometer was immersed in the acid liquid ncar the upper plate; and the wires from the plates were attached to a dead-beat D'Arsonval galvanometer. The liquids were not stirred during the experiments.

With the lower plate at $14^{\circ} \mathrm{C}$, and the upper one at $95^{\circ} \mathrm{C}$., in the dilute nitric acid, a thermoelectric current of about -00004 ampere was produced. At the same temperature, in the dilute sulphuric acid, the strength of current produced was about $\cdot 00001$ ampère. The current flowed from the cold plate through the liquid to the hot one in each case. As platinum is a thermoelectro-positive substance, though in a feeble degree, in metallic couples, these results indicate that both these liquids were thermoelectro-positive, and much more strongly so than platinum.

The electromotive forces of these couples during a state of balanced current were measured by means of a modified form of Poggendorff's method; and the values found were as follows:- With the plates at $14^{\circ}$ and $95^{\circ} \mathrm{C}$. in the dilute nitric acid, $\cdot 418$ volt; in the dilute sulphuric acid, $\cdot 282$ volt; and in a mixture of one volume of hydrochloric acid and ten of water, $\cdot 208$ volt.

The amounts of "surface-resistance" were also measured by using a rheostat as a slide-wire bridge; the same electrodes, with the same amounts of inmersed surface, being employed as were used in the thermoelectric experiments. 
The electrodes faced each other at about $5.0 \mathrm{~cm}$. apart in the respective liquids in a glass cup, the one which was positive in the thermo-couple being used as the anode; and the strengths of current employed were the same as the thermoelectric ones, because I have found that an alteration of strength of current affects the amount of "transfer-resistance." One terminal of a Thomson's reflecting-galvanometer of $3040 \mathrm{ohms}$ resistance was connected with the slider ; and the other connected, first to the anode (or cathode), and then to a vertical platinum wire (or idle electrode) immersed in the liquid close to the anode (or cathode) but not touching it; a balance being obtained in each case by moving the slider.

In the dilute nitric acid, with a current of $\cdot 00004$ ampère, the amounts of "surface-resistance" were:-

$$
\text { At } 14^{\circ} \mathrm{C} \text { At } 95^{\circ} \mathrm{C} \text {. }
$$

At the anode . . 49266 ohms. 531 ohms. At the cathode . $29784, " 494 "$

By a rise of temperature, therefore, of one of the pieces of platinum of the thermoelectric couple 81 Centigrade degrees, the amount of "surface-resistance" of that piece was reduced, as a cathode or in the direction of the thermoelectric current, 98.34 per cent., and in the opposite direction, or as an anode, 98.92 per cent.; and the total "surface-resistance" in the circuit was also reduced 37.05 per cent. in the direction of that current, and $61 \cdot 65$ per cent. in the opposite one.

The results also show that the cold platinum offered 39.55 per cent., and the hot platinum 6.97 per cent., less amount of "surface-resistance" as a cathode than as an anode; also that the total amount of such "resistance" in the two directions in the circuit, when one of the junctions was heated to $94^{\circ} \mathrm{C}$., was $64^{\circ} 14$ per cent. greater in the direction of the thermoelectric current produced than in the opposite one.

In the dilute sulphuric acid, with a current of 00001 ampère, the amounts of "surface-resistance" were :-

$$
\text { At } 14^{\circ} \mathrm{C} \text {. At } 95^{\circ} \mathrm{C} \text {. }
$$

At the anode . . 63500 ohms.

At the cathode . . 18550,

3848 ohms.

2152 ,

By a rise of temperature, therefore, of one of the pieces of platinum of the thermoelectric couple 81 C. degrees, the amount of "surface-resistance" of that piece was reduced in the direction of the thermoelectric current, or as a cathode, 88.27 per cent., and in the opposite direction, or as an anode, 93.94 per cent.; and the total "surface-resistance" in the circuit was also reduced $19 \cdot 79$ per cent. in the direction of that current, and $72 \cdot 88$ per cent. in the opposite one. 
The results also show that the cold platinum had $71 \cdot 10$ per cent. and the hot platinum 44.08 per cent. less amount of "surface-resistance" as a cathode than as an anode; also that the total amount of such "resistance" in the two directions in the circuit, when one of the junctions was heated to $94^{\circ} \mathrm{C}$., was 195.75 per cent. greater in the direction of the thermoelectric current than in the opposite one.

The results obtained with these two liquids show that the amount of "surface-resistance" at each junction of such thermoelectric couples varies very greatly with temperature; and that the amount of such "resistance" to the passage of a current in either direction was more largely decreased by rise of temperature with the dilute nitric than with the sulphuric acid. I had previously found with thermoelectric couples composed of metals and electrolytes, "that by rise of temperature 'transfer-resistance' was usually and considerably reduced." (Proc. Roy. Soc , 1885, No. 236, p. 210.)

The direction of thermoelectric current produced in each of these two cases was the same as that indicated by the relative amounts of " surface-resistance" in opposite directions at the heated junction, but the reverse of that indicated by the relative total amounts of such "resistance" in opposite directions in the entire circuit.

As in exch of the two couples, the total amount of " surfaceresistance" in the circuit, when one of the junctions was heated, was very much greater in the direction of the thermoelectric current produced than in the opposite one, I conclude that the direction of that current was not chiefly determined by the alteration of such " resistance" by rise of temperature. The thermoelectric action and the "surface-resistance" therefore appear to be largely distinct phenomena; and as both liquid and metal in those couples were thermoelectropositive substances, the direction of the current was probably caused chiefly by the thermoelectro-positive potential of the liquid increasing more rapidly than that of the metal by rise of temperature. We may also infer that the strength of the thermoelectric current in those couples was very largely increased by the great diminution of "surface-resistance."

In a paper on "Some Relations of Heat to Voltaic and Thermoelectric Action of Metals in Electrolytes" (Proc. Royal Soc. 1884, No. 233, pp. 251-290), I have shown by numerous experiments that "when metals in electrolytes were heated they were more frequently rendered electropositive than negative, in the proportion of about 2.8 to 1.0 ; the proportion in strong solutions was about 3.27 to $1 . "$

Second.-With regard to voltaic couples. As heat affects 
largely the amount of "surface-resistance," and the strength of current, in a thermoelectric couple composed of a metal and an electrolyte, we may infer that it would also, chiefly by altering that " resistance," affect the strength of current in a voltaic cell.

In order to experimentally examine this, the lower platinum plate in the thermoelectric apparatus, already described, was replaced by a rod of amalgamated zine $8.0 \mathrm{~mm}$. long and $2.0 \mathrm{~mm}$. thick; the upper platinum plate being retained in its place. The tube was then filled with the cold mixture of one volume of sulphuric acid and ten of water.

With the entire apparatus and liquid at $14^{\circ} \mathrm{C}$., the electromotive force (determined by the above-named method) was .704 volt, and the strength of current without additional resistance in the circuit was 022 ampère.

With the platinum plate and upper portion only of the liquid at $95^{\circ} \mathrm{C}$., and the zine electrode and liquid around it at $14^{\circ} \mathrm{C}$., the electromotive force was 763 volt, and the strength of current $\cdot 0705$ ampere.

These results show that the electromotive force was increased about 8.38 per cent., and the strength of current 220 per cent., or to $3 \cdot 2$ times its original amount, by raising the temperature of the platinum negative plate $81 \mathrm{C}$. degrees. This increase of strength of current was about 24 per cent. greater than when the lower plate was composed of platinum. This great increase of current was, I consider, largely due to decrease of "surface-resistance" at the negative plate, and in some measure also to the increase of electromotive force attending increased thermoelectro-positive potential of the liquid; also to several other manifest but minor circumstances, such as diminished conduction-resistance of the liquid, \&c.

Third.-With regard to the thermoelectric phenomena of metals. Some experiments were made to try and detect any special degree of resistance at the junctions of ordinary metallic thermoelectric couples, in the following manner :-

The first couple consisted of a smooth horizontal bar of bismuth, and one of antimony, soldered end to end; each bar being $2.0 \mathrm{~cm}$. long, $\cdot 7 \mathrm{~cm}$. wide, and $\cdot 5 \mathrm{~cm}$. thick. Whilst a current of $\cdot 2$ ampere was being passed from one end of the bar to the other, the ends of two thin copper wires, about $1.0 \mathrm{~cm}$. apart, forming the terminals of a Thomson's reflectinggalvanometer of $3040 \mathrm{ohms}$ resistance, were slid very slowly at right angles to and in a horizontal direction, from one end to the other, to and fro, along the upper surface of the couple; the direction of voltaic current being occasionally reversed. Under these conditions, a small portion of the current passed 
through the galvanometer. There was no sudden change in the deflection of the needles at any time when the wires crossed the junction of the two bars. A similar negative result occurred when a thermo-couple formed of iron and German-silver wires $1.5 \mathrm{~mm}$. diameter was employed; and also when a pair composed of platinum wire and mercury was used.

Had there existed a difference of resistance equal to 001 ohm at the junction in either case, it would probably have been detected. I conclude, therefore, that if "surface-resistance" of any kind exists at the junctions of metallic thermoelectric couples, it must be exceedingly small in amount, and that it does not sensibly affect the direction or strength of the currents produced by them.

Some attempts were made to ascertain whether the amount of "transfer-resistance" at an electrode formed of a loop of platinum wire was affected by passing a separate current of electricity through it simply as a conductor, but the results were not satisfactory.

Several of the results of experiments described in this paper agree with the conclusion that differences of "transferresistance" are incapable of producing a current, and are essentially unlike differences of electric potential; also, that heat decreases " transfer-resistance " whilst increasing contactpotential in metal-electrolyte thermoelectric couples.

XXII. On the Numerics of the Elements.-Part II. $B y$ EDMund J. Milus, D.Se., F.R.S.**

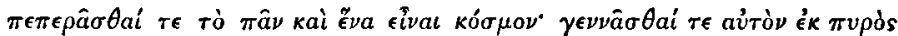

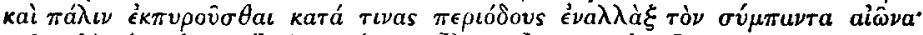

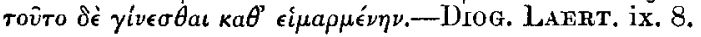

Contents.-Introduction.-New Data and Verifications.-Genesis of the Elements.-Scale of Celestial Temperature.-Variable Stars.Classification of the Elements.-Polymers.-Periodicity.-Evenness. -Frequency.-Table of the Elements.

T Part I. $\dagger$ I have shown that the Numerics of the Elements, 1 so far as they have been accurately determined, may all be expressed by the equation

$$
y=p n-n\left(\frac{n}{n+1}\right),
$$

* Communicated by the Author.

† For Part I. see Phil. Mag. [5] vol. xviii. p. 393 (1884). 